\title{
Additive Manufacturing of Cobalt-Based Dental Alloys: Analysis of Microstructure and Physicomechanical Properties
}

\author{
Leonhard Hitzler $\left(\mathbb{D},{ }^{1,2}\right.$ Frank Alifui-Segbaya $\mathbb{D}^{0},{ }^{3}$ Philipp Williams, ${ }^{4}$ Burkhard Heine, ${ }^{4}$ \\ Michael Heitzmann, ${ }^{5}$ Wayne Hall, ${ }^{1}$ Markus Merkel, ${ }^{4}$ and Andreas Öchsner ${ }^{6}{ }^{6}$ \\ ${ }^{1}$ School of Engineering and Built Environment, Griffith University, Southport, Australia \\ ${ }^{2}$ Institute of Materials Science and Mechanics of Materials, Technical University of Munich, Garching, Germany \\ ${ }^{3}$ School of Dentistry and Oral Health, Griffith University, Southport, Australia \\ ${ }^{4}$ Faculty of Mechanical Engineering and Materials Science, Aalen University of Applied Sciences, Aalen, Germany \\ ${ }^{5}$ School of Mechanical and Mining Engineering, The University of Queensland, Brisbane, Australia \\ ${ }^{6}$ Faculty of Mechanical Engineering, Esslingen University of Applied Sciences, Esslingen, Germany
}

Correspondence should be addressed to Leonhard Hitzler; hitzler@wkm.mw.tum.de and Frank Alifui-Segbaya; f.alifui-segbaya@ griffith.edu.au

Received 30 May 2018; Revised 23 August 2018; Accepted 9 October 2018; Published 11 November 2018

Academic Editor: Zhonghua Yao

Copyright (c) 2018 Leonhard Hitzler et al. This is an open access article distributed under the Creative Commons Attribution License, which permits unrestricted use, distribution, and reproduction in any medium, provided the original work is properly cited.

\begin{abstract}
The limitations of investment casting of cobalt-based alloys are claimed to be less problematic with significant improvements in metal additive manufacturing by selective laser melting (SLM). Despite these advantages, the metallic devices are likely to display mechanical anisotropy in relation to build orientations, which could consequently affect their performance "in vivo." In addition, there is inconclusive evidence concerning the requisite composition and postprocessing steps (e.g., heat treatment to relieve stress) that must be completed prior to using the devices. In the current paper, we evaluate the microstructure of ternary cobaltchromium-molybdenum (Co-Cr-Mo) and cobalt-chromium-tungsten (Co-Cr-W) alloys built with direct metal printing and LaserCUSING SLM systems, respectively, at $0^{\circ}, 30^{\circ}, 60^{\circ}$, and $90^{\circ}$ inclinations $(\Phi)$ in as-built $(\mathrm{AB})$ and heat-treated $(\mathrm{HT})$ conditions. The study also examines the tensile properties (Young's modulus, $E$; yield strength, $R_{\mathrm{P} 0.2}$; elongation at failure, $A_{\mathrm{t}}$; and ultimate tensile strength, $R_{\mathrm{m}}$ ), relative density (RD), and microhardness (HV5) and macrohardness (HV20) as relevant physicomechanical properties of the alloys. Data obtained indicate improved tensile properties and HV values after a short and cost-effective heattreatment cycle of Co-Cr-Mo alloys; however, the process did not homogenize the microstructure of the alloy. Annealing heat treatment of Co-Cr-W led to significant isotropic characteristics with increased $E$ and $A_{\mathrm{t}}$ (except for $\Phi=90^{\circ}$ ) in contrast to decreased $R_{\mathrm{P} 0.2}, R_{\mathrm{m}}$, and $\mathrm{HV}$ values, compared to the $\mathrm{AB}$ form. Similarly, the interlaced weld-bead structures in $\mathrm{AB} C \mathrm{Co}-\mathrm{Cr}-\mathrm{W}$ were removed during heat treatment, which led to a complete recrystallization of the microstructure. Both alloys exhibited defect-free microstructures with RD exceeding 99.5\%.
\end{abstract}

\section{Introduction}

The high strength and stainless nature of ternary cobaltchromium-molybdenum (Co-Cr-Mo) and cobalt-chromiumtungsten (Co-Cr-W) alloys, first patented in 1907 by Haynes, led to the development of compositional variants of cobaltbased alloys for clinical applications such as artificial knee and hip joints and denture frameworks for fixed and removable prostheses [1]. In dentistry, the first use of a cobalt-based alloy for investment casting is reported to have started in 1936 [2]. This was three decades after William Taggart invented a practical method for casting gold inlays [3]. Although casting or "lost-wax" technique is still popular in the dental technology, the steps involved are time-consuming and fraught with processing variables. In light of this, the advent of selective laser melting (SLM) could indeed be considered a watershed as it is claimed to offer significant benefits in terms of manufacturing speed. Since the devices are digitally 
built, they are likely to produce predictable clinical outcomes and be much closer to manufacturers' specification [4-6]. SLM is a metal additive-manufacturing (AM) process that employs high-energy laser beams to melt powders together, in a layer-by-layer fashion, into three-dimensional (3D) objects. However, it is a complex thermophysical process, which is dependent on many parameters including alloying constituents, machines, and the parameters of the controlled environment [6]. One of the potential limitations of the process is that the devices are likely to display mechanical anisotropy in relation to build orientations and this could affect their performance "in vivo" [7-10]. While a few studies [11, 12] have attempted to investigate this limitation, there is inconclusive evidence concerning requisite composition and postprocessing steps (e.g., heat treatment to relieve residual stress) [13] that must be completed prior to using the devices. In the current paper, we evaluate the microstructure of commercially available ternary Co-Cr-Mo (ST2724G) and Co-Cr-W (Remanium CL) alloys, marketed for dental application. Samples were built with direct metal printing and LaserCUSING SLM systems, respectively, at $0^{\circ}, 30^{\circ}, 60^{\circ}$, and $90^{\circ}$ inclinations to the layering (polar angle $\left.\Phi\right)$ in "as-built" $(\mathrm{AB})$ and "heat-treated" (HT) forms. The study also evaluates the tensile properties (Young's modulus, E; yield strength, $R_{\mathrm{P} 0.2}$; elongation at failure, $A_{\mathrm{t}}$; and ultimate tensile strength, $R_{\mathrm{m}}$ ), relative density (RD), and microhardness (HV5) and macrohardness (HV20) as relevant physicomechanical properties of the alloys.

\section{Experimental}

2.1. Specimen Preparation. AB and HT Co-Cr-Mo samples (Co Bal Cr 29; Mo 5.5; $\mathrm{Si}<1 ; \mathrm{Mn}<1$; $\mathrm{Fe}<1$ wt.\%) [14] were built with Type 5 ST2724G alloy (SINT-TECH Parc Européen d'Entreprises, Rue Richard Wagner 63200 Riom, France), whereas Co-Cr-W counterparts (Co Bal Cr 28; W 9; Si 1.5; $\mathrm{Mn}<1 ; \mathrm{Fe}<1 ; \mathrm{Nb}<1 ; \mathrm{N}<1$ wt.\%) [15] were built with the Remanium star CL alloy (Dentaurum GmbH \& Co. KG, Turnstraße 31,75228 Ispringen, Germany) at $0^{\circ}, 30^{\circ}, 60^{\circ}$, and $90^{\circ}$ inclinations, subsequently referred to as polar angle $(\Phi)$. The ST2724G raw powder had a powder density of $4.1 \mathrm{~g} / \mathrm{cm}^{3}$ and an average particle size $\left(D_{50}\right)$ of $8-9 \mu \mathrm{m}$. Figure 1 shows the schematic of sample orientations. For Co-Cr-Mo specimens, a dumbbell-shaped CAD model (SolidWorks; Dassault Systèmes SolidWorks Corp., 300 Baker Avenue, Concord, MA 01742) designed in accordance with ISO 22674 requirements [16] was sent to 3D Systems (Rue Richard Wagner, 63200 Riom, France), and the samples were built at a layer thickness of $30 \mu \mathrm{m}$ in an inert environment using a ProX DMP 200 printer [17]. The heat treatment for Co-Cr-Mo was completed in an airy furnace at $800^{\circ} \mathrm{C}$ for 20 minutes by the manufacturer (as recommended for dental devices) prior to the removal of the support structures (Mark Barnes Engineering, 35 Olympic Circuit, Southport QLD 4215, Australia) Unlike the directly built CoCr-Mo specimens, Co-Cr-W samples were supplied as $7 \mathrm{~mm}$ $\times 55 \mathrm{~mm}$ cylindrical bars built in an inert environment using an Mlab printer (Concept Laser GmbH, An der Zeil 8, 96215

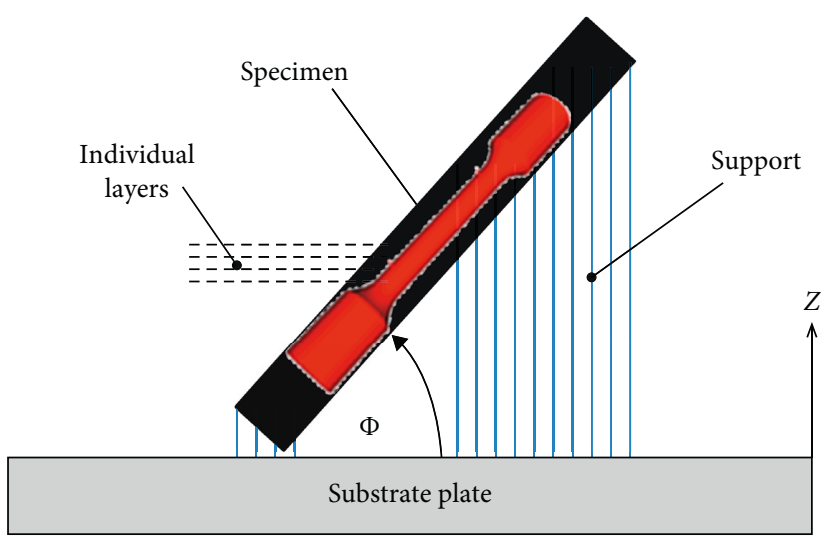

FIgURE 1: Schematic of sample orientations and description via the polar angle $(\Phi) ; \Phi=0^{\circ}$ equals sample orientation parallel to the layers, and $\Phi=90^{\circ}$ is the perpendicular alignment.

Lichtenfels, Germany). Heat treatment was completed by the supplier in a furnace under argon atmosphere at a rate of $400^{\circ} \mathrm{C} /$ hour to $1150^{\circ} \mathrm{C}$ followed by a $1 \mathrm{~h}$ dwell time before cooling down to $300^{\circ} \mathrm{C}$ [18]. This particular treatment is recommended by Concept Laser for the Co-Cr-W alloy for dental applications. The cylindrical samples were turned on a CNC milling machine (Griffith Technical Solutions, Nathan Campus, Griffith University, 170 Kessels Road QLD 4111, Australia) using cooling emulsion to minimize possible alterations to their microstructure.

2.2. Microstructural Analysis. The microstructure analysis involved optical examination of randomly selected test specimens for grain size, porosity and voids, dendritic growth, cracks, and other defects. Four grinding and mechanical polishing steps were performed to expose the metallurgical structure. The steps comprised grinding with silicon carbide $(\mathrm{SiC}) 220$ sandpaper, polishing process with $9 \mu \mathrm{m}$ and $3 \mu \mathrm{m}$ diamond suspension, and surface finishing with a silicon monoxide $(\mathrm{SiO})$ solution with a grain size of $0.5 \mu \mathrm{m}$. The visibility of the scan track pattern and the inherent grain structure was enhanced by a subsequent etching process. Two etching procedures were employed: etching with "Beraha 3" acid (comprising $60 \mathrm{ml} \mathrm{H} \mathrm{H}_{2} 0,40 \mathrm{ml}$ hydrochloric acid, $5 \mathrm{~g}$ ammonium hydrogen difluoride, and $1 \mathrm{~g}$ potassium bisulphite) and electrochemical etching at $3 \mathrm{~V}$ for 10 seconds in a 3\% hydrochloric acid solution. Highresolution images of the etched microsections were taken with an optical light microscope (Axio Imager z2m; Carl Zeiss Microscopy GmbH, Jena, Germany). In determining the $\mathrm{RD}$, area porosities were calculated on the micrographs with the Zeiss AxioVison software package (Carl Zeiss Microscopy GmbH, Jena, Germany).

2.3. Tensile Test. Tensile testing to assess Young's modulus (E), $0.2 \%$ yield strength $\left(R_{\mathrm{P} 0.2}\right)$, elongation at failure $\left(A_{\mathrm{t}}\right)$, and ultimate tensile strength $\left(R_{\mathrm{m}}\right)$ was performed as per ISO 22674:2016 guidelines [19] Test specimens $(n \geq 3)$ from each configuration and condition (inclination and treatment) 
were subjected to uniaxial tensile loading and stressed until failure occurred.. Specimens (gauge diameter $3 \mathrm{~mm}$, gauge length $15 \mathrm{~mm}$, and radial shoulders) were tested to yield at a maximum load of $10 \mathrm{kN}$ and $1.5 \mathrm{~mm} / \mathrm{min}$ cross-head speed using an Instron 5584 tensile testing machine with an inbuilt video extensometer type 2663-821 (Instron Corp., Norwood, MA, USA). Applied nomenclature for the tensile properties is in accordance with DIN EN ISO 6892-1:2009 [20].

2.4. Hardness Test. Vickers hardness (HV) tests were perfomed with a Struers Durascan 70 G5 hardness tester (Struers GmbH, Kernen im Remstal, Germany) in accordance with DIN EN ISO 6507-2:2016 test guidelines [21] to measure the microhardness (HV5) and macrohardness (HV20) of the alloys, using 49.03 $\mathrm{N}$ and $196.1 \mathrm{~N}$ indentation force, respectively.

\section{Results}

For microstructure analysis, only images from crosssectional micrographs are presented in the paper due to the configurational similarities and corresponding redundancy of longitudinal micrographs (Figure 2). For instance, the cross-sectional cut of a $0^{\circ}$ orientated specimen is similar to the longitudinal cut of a $90^{\circ}$ specimen; likewise, the cross-sectional cut of a $30^{\circ}$ inclined specimen matches the longitudinal cut of a $60^{\circ}$ specimen. Figure 3 shows the obtained area porosities of both alloys, measured on the microsections. The relative density (RD) is $99.93 \%$ for Co$\mathrm{Cr}-\mathrm{Mo}$ and $99.86 \%$ for $\mathrm{Co}-\mathrm{Cr}-\mathrm{W}$, respectively. Relative densities obtained via microsections result generally in higher percentages compared to the determination via the Archimedes method [22]. On the $90^{\circ}$ inclined $\mathrm{Co}-\mathrm{Cr}-\mathrm{W}$ sample, small delaminations induced spikes in area porosity. In Figures 4 and 5, the microstructures of Co-Cr-Mo and $\mathrm{Co}-\mathrm{Cr}-\mathrm{W}$ specimens are depicted for each inclination and both conditions, i.e., $\mathrm{AB}$ and HT conditions for the left and right columns, respectively. The tensile test data are summarized in Table 1, while Figure 6 shows representative stress-strain graphs of the alloys. Figure 7 compares and summarizes Young's modulus $(E)$ data of the alloys after heat treatment as per dependency on the inclination angle. Figure 8 presents the graphical summaries of the yield strength $\left(R_{\mathrm{P} 0.2}\right)$, elongation at failure $\left(A_{\mathrm{t}}\right)$, and ultimate tensile strength $\left(R_{\mathrm{m}}\right)$. In addition, the corresponding minimum requirements stated in the ISO 22674 standard [16] are included in the graphical summaries as well. Lastly, microhardness (HV5) and macrohardness (HV20) results are summarized in Figure 9.

\section{Discussion}

While in the mouth, dental devices are subjected to stress from masticatory actions; hence, alloys should show high recovery capacity, resilience, high specific stiffness $(E / R D)$, and elongation, if devices are to withstand biting forces without fracture [23]. Figure 10 shows an illustration of a denture framework with different functional parts, such as

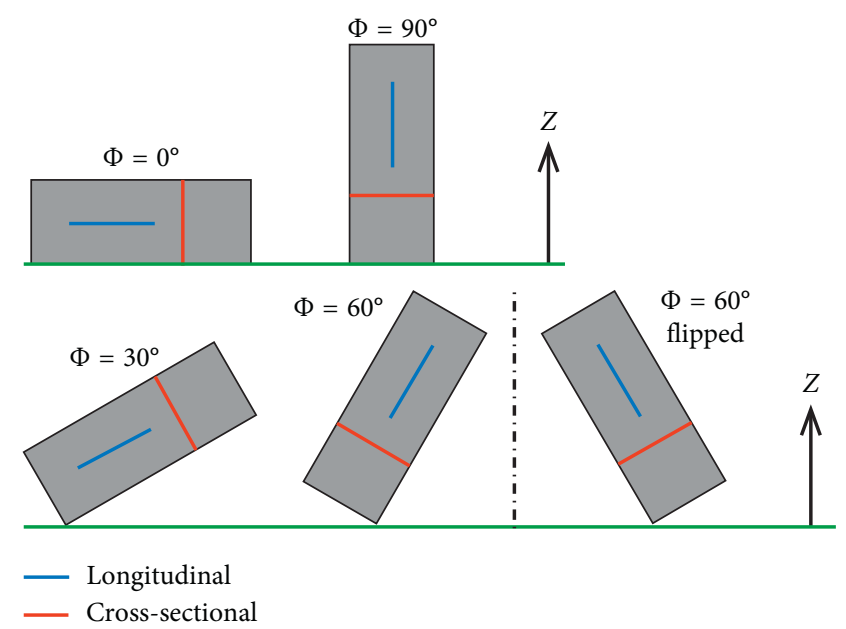

Figure 2: Configurational similarities in longitudinal and crosssectional test samples.

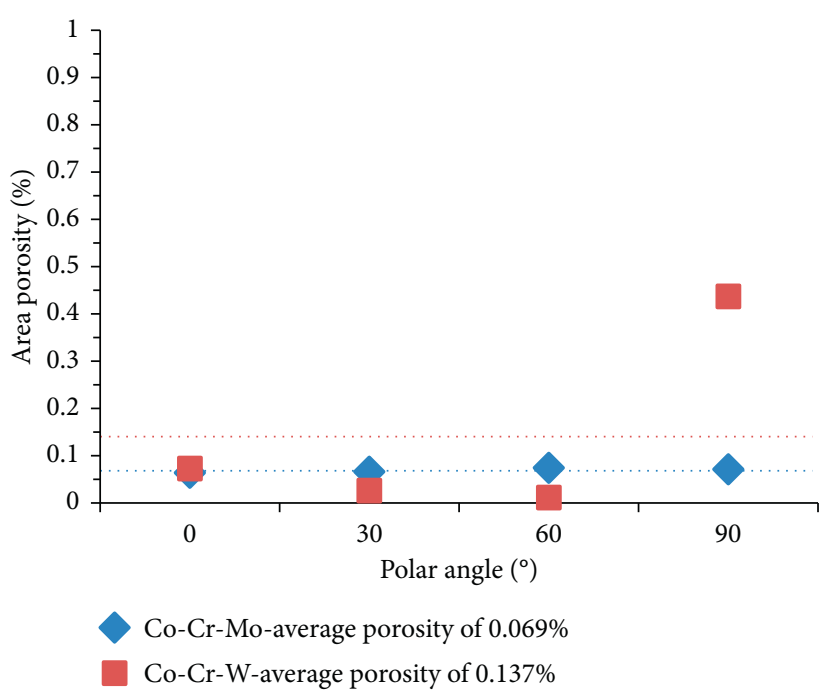

Figure 3: Area porosity of Co-Cr-Mo and Co-Cr-W alloys.

clasp components and connectors. These parts explain the importance of orientation-dependent fluctuations in the material characteristics, which are present in selective lasermelted metals.

The standards for assessing the mechanical properties of dental alloys [19] place emphasis on $E, A_{\mathrm{t}}$, and $R_{\mathrm{P} 0.2}$ of the alloys. In a clinical context, $R_{\mathrm{P} 0.2}$ is relevant for predicting failure in multiple unit dental bridges. $A_{\mathrm{t}}$ determines how the alloys can sustain a large permanent deformation before they fracture. It is worth noting that $A_{\mathrm{t}}$ could serve as a quality control measure that verifies the level of impurities and proper processing of the devices, while $E$ measures the alloy's ability to resist flexure, especially in metalceramic restorations where flexure will cause fracture of the porcelain [24]. Literature about alloys provides information on their hardness; while a low value cannot resist occlusal forces, an extremely high value could make the alloy difficult to grind and polish and even wear the 


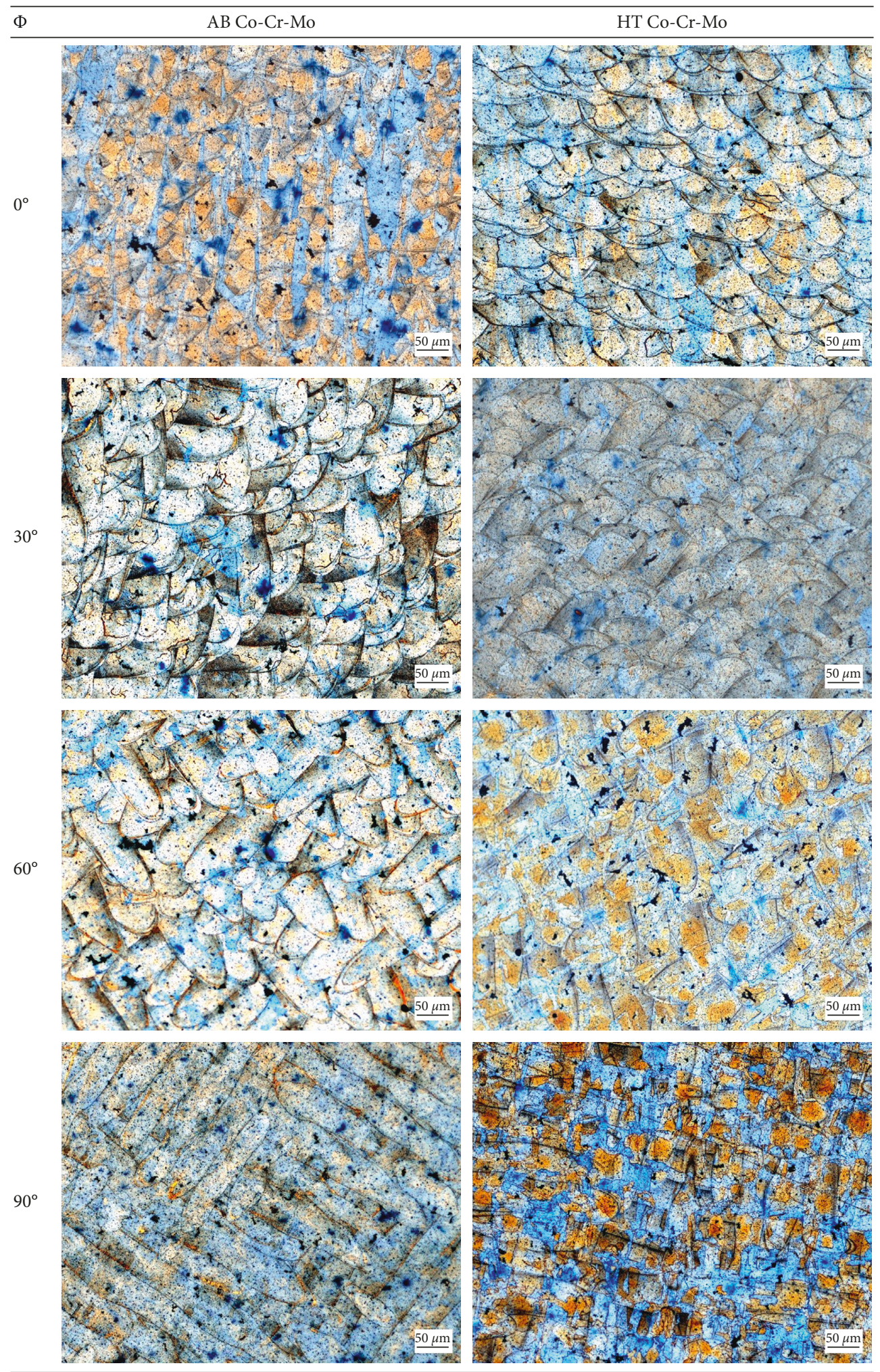

Figure 4: Microstructure $(50 \mu \mathrm{m})$ of $\mathrm{AB}$ and HT Co-Cr-Mo specimens.

opposing teeth [23]. Table 2 summarizes the tensile properties as a range, i.e., respective minima and maxima for alloys examined in comparison to data from alloy manufacturers and standard requirements for dental alloys.
4.1. Microstructural Analysis. SLM-produced Co-Cr alloys are reported to display superior homogeneity compared to cast Co-Cr alloys, which are inherently associated with large initial grain size, nonhomogeneities, and other casting defects [6]. 


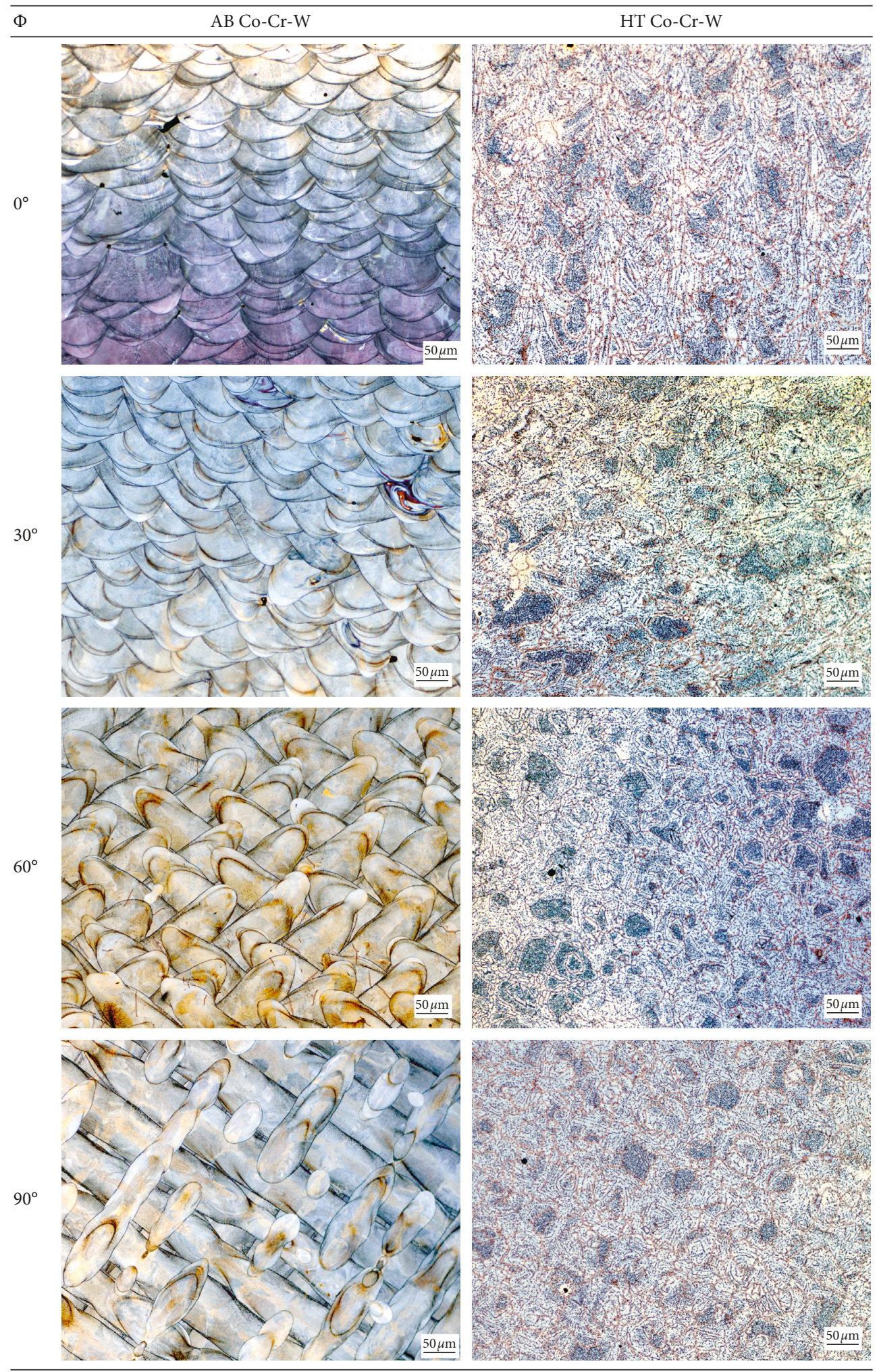

Figure 5: Microstructure $(50 \mu \mathrm{m})$ of $\mathrm{AB}$ and $\mathrm{HT}$ Co-Cr-W specimens.

4.1.1. Relative Density. The evaluated area porosities on the micrographs revealed average RDs greater than $99.8 \%$ and individual RDs greater than $99.5 \%$ in all cases. Since the applied heat treatment in this study did not comprise a hot isostatic pressing (HIP), which could enhance the RD further, it can be concluded that the post-heat-treatment did not alter the RD of the specimens [26]. It is worth stating that the observed density does not negate a possible inhomogeneity at the increasing build height [9]. Given that the criterion applied in the aeronautics industry for 
TABle 1: Tensile properties of Co-Cr-Mo and Co-Cr-W.

\begin{tabular}{|c|c|c|c|c|c|c|c|c|}
\hline \multirow[t]{2}{*}{ Alloy, condition, and inclination $(\Phi)$} & \multicolumn{2}{|c|}{$\begin{array}{l}\text { Young's modulus } \\
E(\mathrm{GPa})\end{array}$} & \multicolumn{2}{|c|}{$\begin{array}{l}\text { Yield strength } \\
R_{\mathrm{P} 0.2}(\mathrm{MPa})\end{array}$} & \multicolumn{2}{|c|}{$\begin{array}{l}\text { Elongation at } \\
\text { failure } A_{\mathrm{t}}(\%)\end{array}$} & \multicolumn{2}{|c|}{$\begin{array}{l}\text { Ultimate tensile } \\
\text { strength } R_{\mathrm{m}} \\
(\mathrm{MPa})\end{array}$} \\
\hline & Mean & SD & Mean & $\mathrm{SD}$ & Mean & $\mathrm{SD}$ & Mean & $\mathrm{SD}$ \\
\hline Co-Cr-Mo $0^{\circ} \mathrm{AB}$ & 98.38 & 17.01 & 702 & 15.4 & 5.7 & 1.04 & 923 & 32.4 \\
\hline Co-Cr-Mo $0_{-}^{\circ} \mathrm{HT}$ & 156.48 & 19.50 & 819 & 29.1 & 13.3 & 2.32 & 1097 & 21.6 \\
\hline Co-Cr-Mo 30AB & 105.32 & 19.39 & 783 & 23.7 & 6.7 & 1.94 & 1102 & 45.2 \\
\hline Co-Cr-Mo $30^{\circ}$ HT & 149.73 & 6.29 & 1002 & 41.1 & 8.3 & 0.81 & 1262 & 14.1 \\
\hline $\mathrm{Co}-\mathrm{Cr}-\mathrm{Mo} 60^{\circ} \_\mathrm{AB}$ & 112.11 & 58.51 & 696 & 34.3 & 7.5 & 2.10 & 1012 & 24.0 \\
\hline Co-Cr-Mo 60﹎HT & 105.67 & 13.18 & 808 & 37.8 & 9.4 & 1.32 & 1054 & 20.9 \\
\hline $\mathrm{Co}-\mathrm{Cr}-\mathrm{Mo} 90^{\circ} \_\mathrm{AB}$ & 100.21 & 6.95 & 674 & 9.0 & 14.8 & 1.62 & 1033 & 12.4 \\
\hline Co-Cr-Mo 90﹎HT & 164.54 & 15.10 & 757 & 7.2 & 16.7 & 1.51 & 1052 & 6.3 \\
\hline $\mathrm{Co}-\mathrm{Cr}-\mathrm{W} 0^{\circ} \_\mathrm{AB}$ & 183.44 & 15.58 & 917 & 9.9 & 11.1 & 1.14 & 1263 & 8.6 \\
\hline Co-Cr-W $0^{\circ}$ HT & 216.32 & 21.99 & 655 & 26.6 & 15.0 & 1.54 & 1111 & 8.9 \\
\hline Co-Cr-W 30﹎AB & 147.50 & 20.57 & 965 & 5.9 & 10.4 & 1.31 & 1272 & 10.3 \\
\hline Co-Cr-W 30 _HT & 186.96 & 7.90 & 651 & 4.9 & 15.5 & 1.04 & 1127 & 12.3 \\
\hline Co-Cr-W 60﹎AB & 167.17 & 26.23 & 845 & 11.1 & 17.1 & 1.35 & 1247 & 6.1 \\
\hline Co-Cr-W 60 ${ }^{\circ} \_\mathrm{HT}$ & 214.51 & 29.25 & 669 & 20.0 & 18.0 & 2.90 & 1162 & 13.4 \\
\hline Co-Cr-W 90_AB & 138.55 & 6.93 & 755 & 8.7 & 24.3 & 0.70 & 1188 & 6.3 \\
\hline Co-Cr-W 90 ${ }^{\circ} \mathrm{HT}$ & 202.35 & 22.08 & 658 & 7.1 & 16.9 & 1.51 & 1108 & 10.9 \\
\hline
\end{tabular}

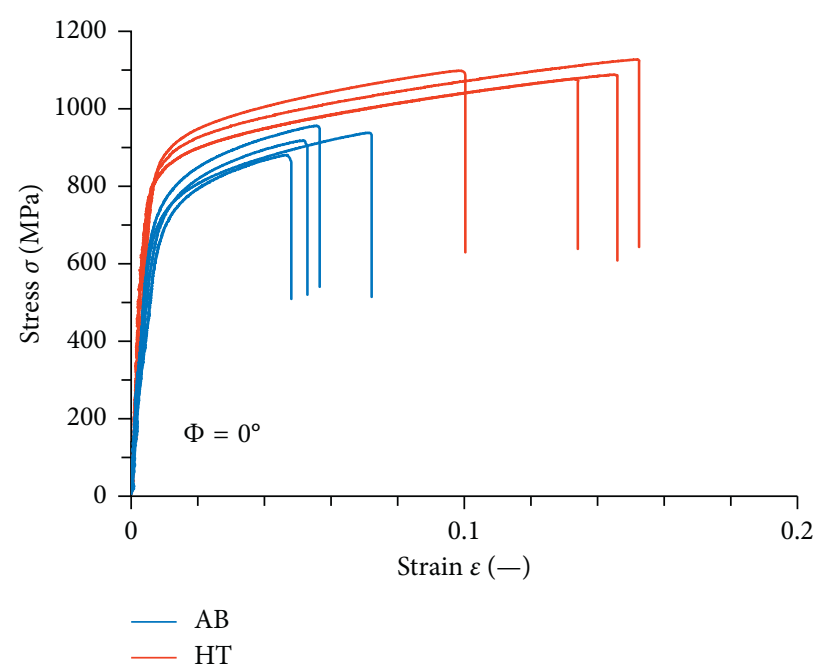

(a)

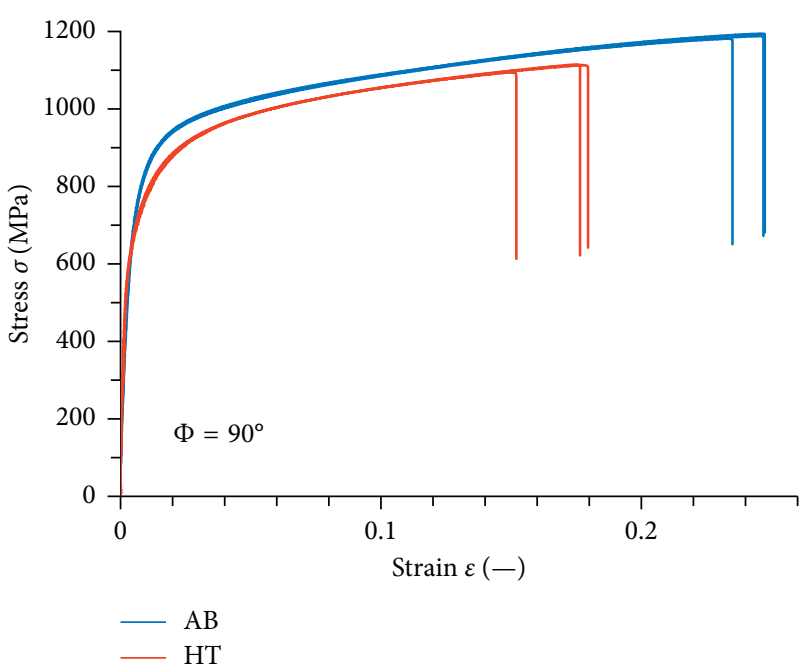

(b)

Figure 6: Representative stress-strain graphs of Co-Cr-Mo (a) and Co-Cr-W (b) alloys.

$\mathrm{RD}$ is greater than $99 \%$, these values could be considered to be exceptional for the manufacturing process [27]. For most applications, such a high $\mathrm{RD}$ is not required and a correlated reduction in mechanical strength is traded for speed and economic fabrication [28-30]. However, for dental metallic devices, the $\mathrm{RD}$ is also relevant to accomplish a tissue-friendly, void-free satin finish, which is achieved via electrolytic polishing to prevent fitting and cleaning problems on the fitting surface of denture frameworks. Given that in SLM the residual porosity tends to be common in the subsurface, which is the transition area between the contour and core irradiation, lower RD could potentially lead to laid open pores after polishing $[10,31,32]$.
4.1.2. As-Built Condition. In the $\mathrm{AB}$ condition, the stacking scheme of the individual weld beads as well as the applied irradiation strategy controls the micrographs (left-hand side in Figures 4 and 5). The absence of needle-like-appearing fine-structured platelets, seen in cast samples, is noteworthy. These are formed at thermodynamic equilibrium conditions at $417^{\circ} \mathrm{C}$ alongside the allotropic transformation from the face-centered cubic (fcc; $\gamma$-Co) to the hexagonal close packed (hcp; $\mathcal{E}$-Co) crystal structure [33]. In investment casting, cooling rates are very slow within the pool of molten ingots, and larger grains are formed around tiny nuclei that grow until the grain boundaries meet the solid state. Because of this, dendritic structures may be very large in cast $\mathrm{Co}-\mathrm{Cr}$ alloys, and the size of a single grain can approach the 


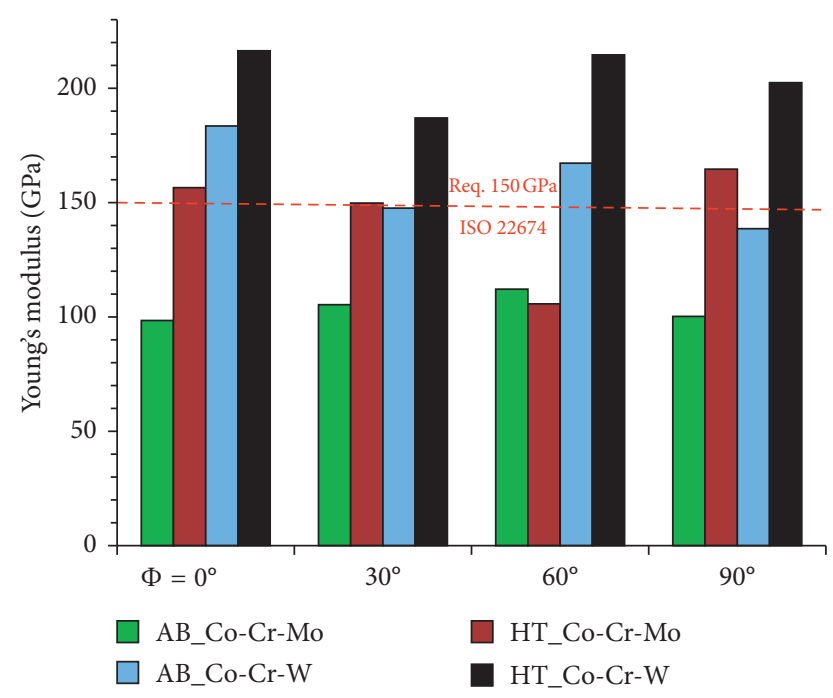

Figure 7: Mean value of $E$ for Co-Cr-Mo and Co-Cr-W alloys.

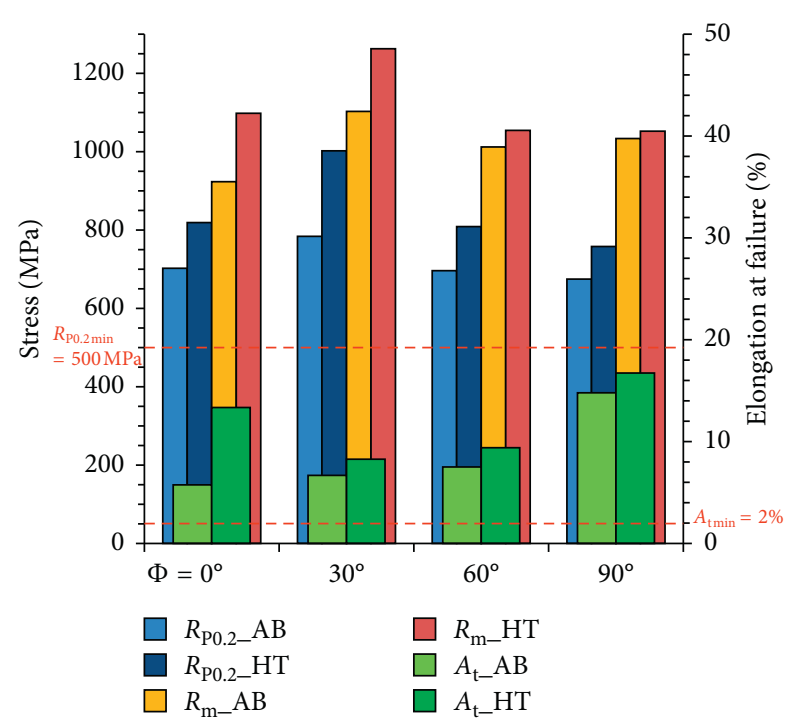

(a)

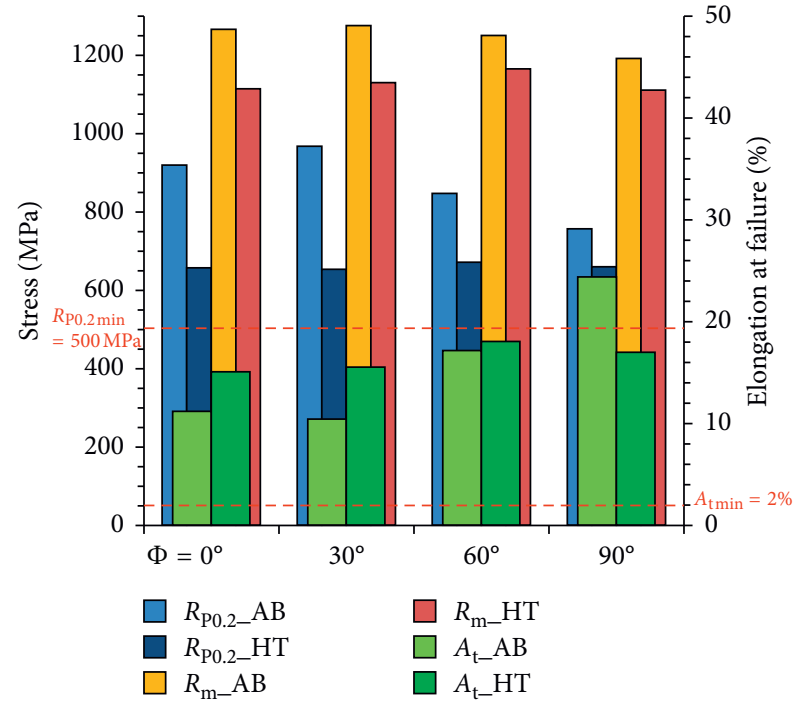

(b)

Figure 8: $R_{\mathrm{P} 0.2}, R_{\mathrm{m}}$, and $A_{\mathrm{t}}$ values for Co-Cr-Mo (a) and Co-Cr-W (b) alloys.

diameter of a removable partial denture framework clasp [5]. Due to the rapid cooling rates in SLM, no large grains or dendritic structures are evident. Moreover, the absence of the platelets indicates that the fcc to hcp transformation did not take place, and the thermodynamic equilibrium was not reached. This suggests that the metastable $\gamma$-Co is present in the as-built condition, which is comparable with a recently published study on heat treatments of additively manufactured Co-Cr-Mo. According to Kajima et al. [34], $\varepsilon$-Co is only present after an additional heat treatment and the volume fraction between $\gamma$-Co and $\varepsilon$-Co varies upon the heattreatment temperature, with $\gamma$-Co remaining as the predominant phase ( $\geq 75 \%$ volume fraction). The transformation of $\gamma$-Co to $\varepsilon$-Co is dependent on the grain size, and for finegrained structures (as is the case in SLM), this transformation is suppressed, resulting in the predominant $\gamma$-Co [35].
4.1.3. Heat-Treated Condition. Heat treatments and modification of elemental composition could change the microstructure and consequently alter the physical-mechanicalchemical properties of Co-based alloys. In SLM, heat treatment is required to remove accumulated thermal stresses in long-span devices [13]. It is worth clarifying that the cycles for both alloys differ significantly. Co-Cr-Mo was heat treated at $800^{\circ} \mathrm{C}$, which induced slow-progressing recrystallization, whereas at $1150^{\circ} \mathrm{C}$ for $\mathrm{Co}-\mathrm{Cr}-\mathrm{W}$, a soft annealing with directional recrystallization occurred. The latter led to a complete restructuration of the microstructure, whereby the stacking scheme of single weld beads was no more visible (Figure 5). At $1150^{\circ} \mathrm{C}, \mathrm{Cr}$ and $\mathrm{W}$ are solved in $\gamma$-Co and a chemically homogeneous situation is given. This step was followed by a very slow cooling (furnace cooling), which ensured thermodynamic equilibrium conditions. In general, 


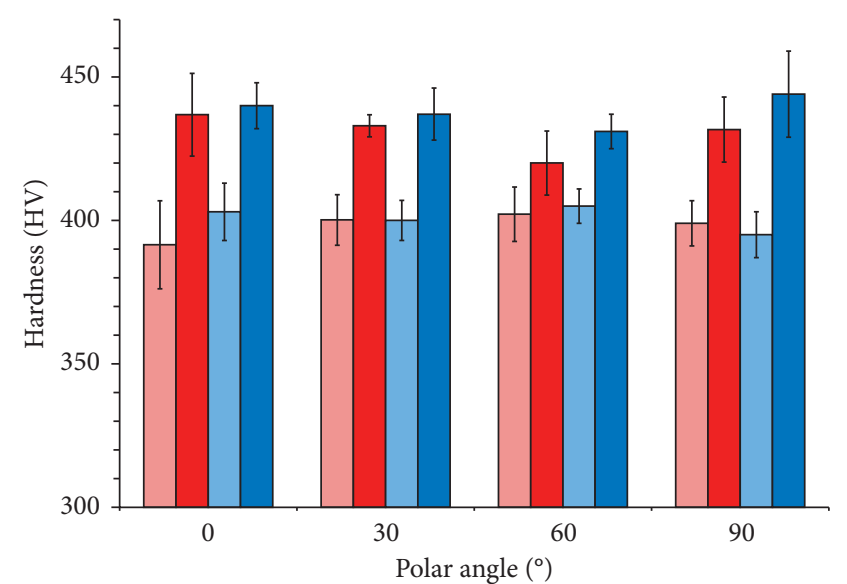

AB_HV5

HT_HV5 $\square$ AB_HV20

$\square$ HT_HV20

(a)

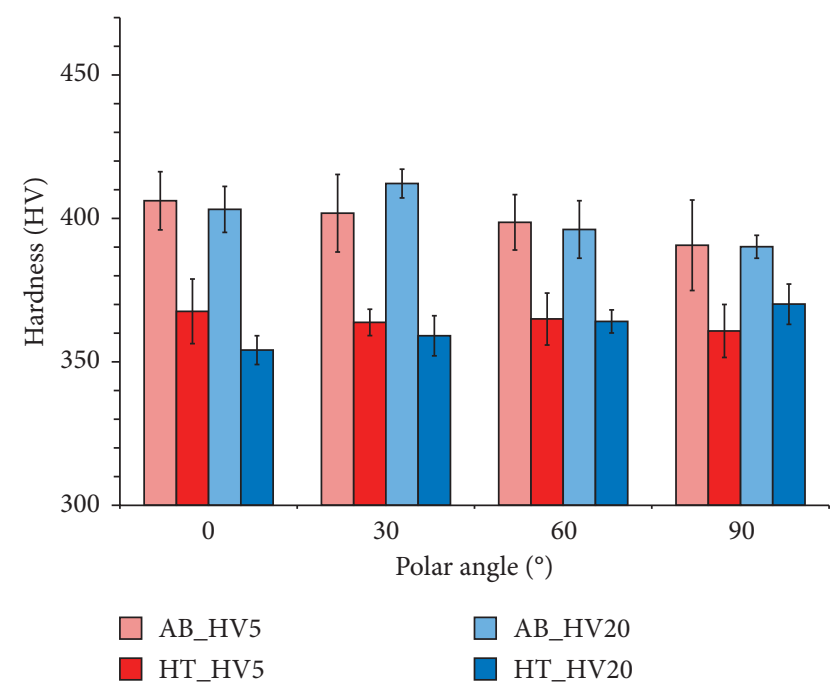

(b)

Figure 9: HV5 and HV20 values for Co-Cr-Mo (a) and Co-Cr-W (b) alloys. Error bars show standard deviation from the mean.

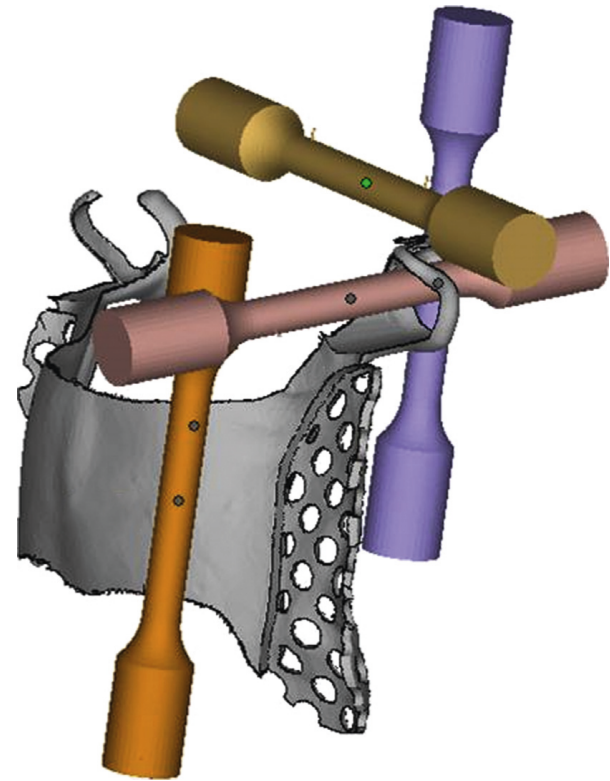

Figure 10: Schematic of a denture framework with different functional parts.

the Co-Cr-W material displayed predominantly isotropic properties with only minor fluctuations after heat treatment, while $E$ was raised significantly and strength and hardness were reduced. Savage [36] explained that the preferred temperature range for the isothermal transformation (notably by lamellar constituent) of the ternary Co-based alloys is about $1040^{\circ} \mathrm{C}$ to $1100^{\circ} \mathrm{C}$ and the length of the isothermal treatment is a function of composition of alloy and temperature of transformation, but in most instances, a one-hour dwell time at the target temperature is sufficient. The isothermal heat treatment at $800^{\circ} \mathrm{C}$ for 20 minutes of Co-Cr-Mo resulted in significantly improved $E$ and slightly increased $R_{\mathrm{P} 0.2}, A_{\mathrm{t}}, R_{\mathrm{m}}$, and HV. An assumption of the origin of the higher and unsystematically varied $R_{\mathrm{m}}$ was given in a study by Turrubiates-Estrada et al. [37]. It was indicated that heat treatment at $800^{\circ} \mathrm{C}$ for 20 minutes promotes the formation of $\varepsilon$-Co and intermetallic precipitations and/or carbides (Figure 11, [38]). According to Kajima et al. [34], heat treatment at $800^{\circ} \mathrm{C}$ for $6 \mathrm{~h}$ can lead to a volume fraction of around 20-25\% $\varepsilon$-Co in SLM samples. The formation of the second phases in a sufficient fine distribution (high undercooling) could be the origin of the observed increase in the mechanical values.

It should be noted that, during the additive formation, the material undergoes several heating cycles. After the main fabrication step, i.e., the raw metal powder being completely molten and rapidly solidified, the solidified volume passes a continuous time-temperature-transformation (TTT) as shown in Figure 12, [38]. During cooling, the observed volume undergoes several postheating cycles by additive formation of further layers on top of the observed volume; hence, it is possible that a considerable fraction of $\varepsilon$-Co can be generated via alterations in the process conduct [10].

4.2. Tensile Properties. All test specimens yielded at the ultimate stress without localized necking. Specimen fracture occurred along the gauge length, indicating the homogeneous nature of the alloys. The overall polar angle dependence of the mechanical properties was low, except for $A_{\mathrm{t}}$, which showed large fluctuations in the $\mathrm{AB}$ condition for both alloys and for Co-Cr-Mo in the heat-treatment condition. These findings confirm the assertion that ductility represents the most volatile tensile characteristic. Our data for polar dependency at $\Phi=90^{\circ}$ corroborate findings by Takaichi et al. [12], but contrast studies that examine Albased [9] and Fe-based [8] metals. This shows that in SLM characteristics on the anisotropy vary and are dependent on raw materials.

Although there are no existing manufacturer data on build orientations for the Co-Cr- Mo alloy used in our study, 
TABLE 2: Tensile properties of alloys in comparison to standards requirements.

\begin{tabular}{|c|c|c|c|c|c|}
\hline & $\begin{array}{l}\text { Young's } \\
\text { modulus } E \\
(\mathrm{GPa}) \\
\end{array}$ & $\begin{array}{l}\text { Yield strength } \\
R_{\mathrm{P} 0.2}(\mathrm{MPa})\end{array}$ & $\begin{array}{l}\text { Elongation at } \\
\text { failure } A_{\mathrm{t}}(\%)\end{array}$ & $\begin{array}{c}\text { Ultimate tensile } \\
\text { strength } R_{\mathrm{m}}(\mathrm{MPa})\end{array}$ & Additional information \\
\hline $\begin{array}{l}\mathrm{AB} \text { Co-Cr-Mo range at } 0^{\circ}, 30^{\circ}, \\
60^{\circ} \text {, and } 90^{\circ} \text { in the current } \\
\text { study }\end{array}$ & $98.38-112.11$ & $674-783$ & $5.7-14.8$ & $923-1102$ & $\begin{array}{l}\text { Recommended heat } \\
\text { treatment for dental parts is } \\
800^{\circ} \mathrm{C} \text { for } 20-25 \mathrm{~min}\end{array}$ \\
\hline $\begin{array}{l}\mathrm{HT} \text { Co-Cr-Mo range at } 0^{\circ}, 30^{\circ} \text {, } \\
60^{\circ} \text {, and } 90^{\circ} \text { in the current } \\
\text { study }\end{array}$ & $105.67-164.54$ & $757-1002$ & $8.3-16.7$ & $1012-1262$ & \\
\hline $\begin{array}{l}\text { AB Co-Cr-Mo data from the } \\
\text { manufacturer as per ASTM E } 8 \\
{[25]}\end{array}$ & $* *$ & $850 \pm 100$ & $10 \pm 2$ & $1200 \pm 100$ & $\begin{array}{l}{ }^{* *} \text { Not provided; } \\
\text { manufacturer's density is } \\
\approx 100 \% \text { in AB and HT } \\
\text { conditions; HV5 after heat } \\
\text { treatment is } 500 \pm 20\end{array}$ \\
\hline $\begin{array}{l}\text { HT Co-Cr-Mo data from the } \\
\text { manufacturer as per ASTM E8 } \\
{[25]}\end{array}$ & $* *$ & $900 \pm 100$ & $15 \pm 2$ & $1260 \pm 100$ & \\
\hline $\begin{array}{l}\mathrm{AB} \text { Co-Cr-W range at } 0^{\circ}, 30^{\circ}, \\
60^{\circ} \text {, and } 90^{\circ} \text { in the current } \\
\text { study }\end{array}$ & $138.55-183.44$ & $755-965$ & $10.4-24.3$ & $1188-1263$ & $\begin{array}{l}\text { Recommended heat } \\
\text { treatment for dental parts is } \\
\text { slow heating }\left(400^{\circ} \mathrm{C} / \mathrm{h}\right) \text { up to } \\
1150^{\circ} \mathrm{C} \text {, followed by a dwell } \\
\text { time of } 1 \mathrm{~h} \text {, and then furnace } \\
\text { cooling to } 300^{\circ} \mathrm{C}\end{array}$ \\
\hline $\begin{array}{l}\mathrm{HT} \text { Co-Cr-W range at } 0^{\circ}, 30^{\circ}, \\
60^{\circ} \text {, and } 90^{\circ} \text { in the current } \\
\text { study }\end{array}$ & $186.96-216.32$ & $651-669$ & $15-18$ & $1108-1162$ & \\
\hline $\begin{array}{l}\text { HT Co-Cr-W data range }\left(0^{\circ},\right. \\
\left.45^{\circ} \text {, and } 90^{\circ}\right) \text { from the } \\
\text { manufacturer }[15]\end{array}$ & 230 & $792-835$ & $8-11$ & $1136-1200$ & $\begin{array}{l}\text { Manufacturer-provided } \\
\text { density at all orientations is } \\
8.6 \mathrm{~g} / \mathrm{cm}^{3}\end{array}$ \\
\hline ISO 22674:2016 [16] & 150 & 500 & 2 & $* *$ & ${ }^{* *}$ Not provided \\
\hline
\end{tabular}

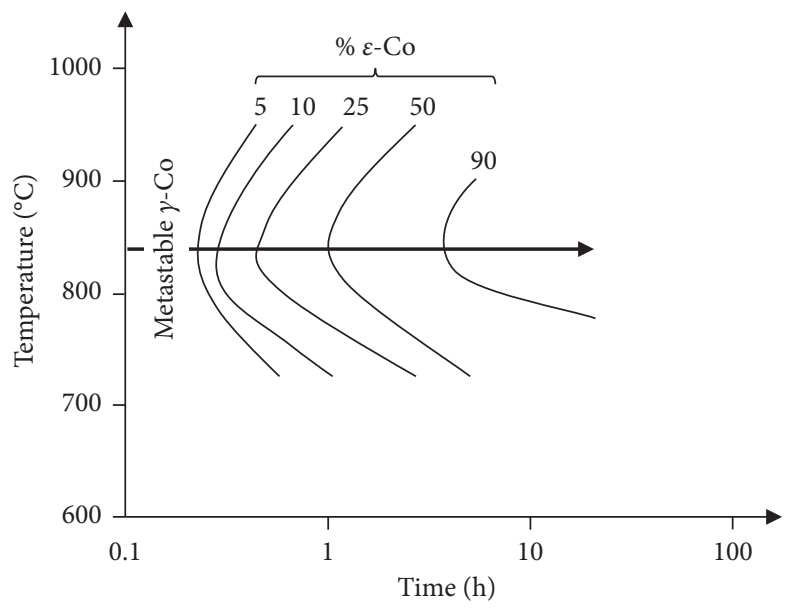

Figure 11: Isothermal TTT diagram of CoCr27Mo5C0.23, adapted from [38].

our data show that Co-Cr-Mo in the $\mathrm{AB}$ form required heat treatment to attain the minimum $E$ value as per standards requirements (except for $\Phi=60^{\circ}$ ). Despite the improved tensile properties and $\mathrm{HV}$ values, the short and costeffective heat-treatment cycle did not completely homogenize the properties of alloys. Both alloys showed increased $E$ after heat treatment, which is related to the increased ratio of $\varepsilon$-Co. Differences in $E$ values for the two alloys are probably due to varying ratios of $\gamma$-Co to $\varepsilon$-Co in the respective structure. Since the phase content is not absolute, it may change during the tensile test via straininduced phase transformation, and the $\varepsilon$-Co fraction can increase [12]. The precise influence of this effect needs to be studied further. 


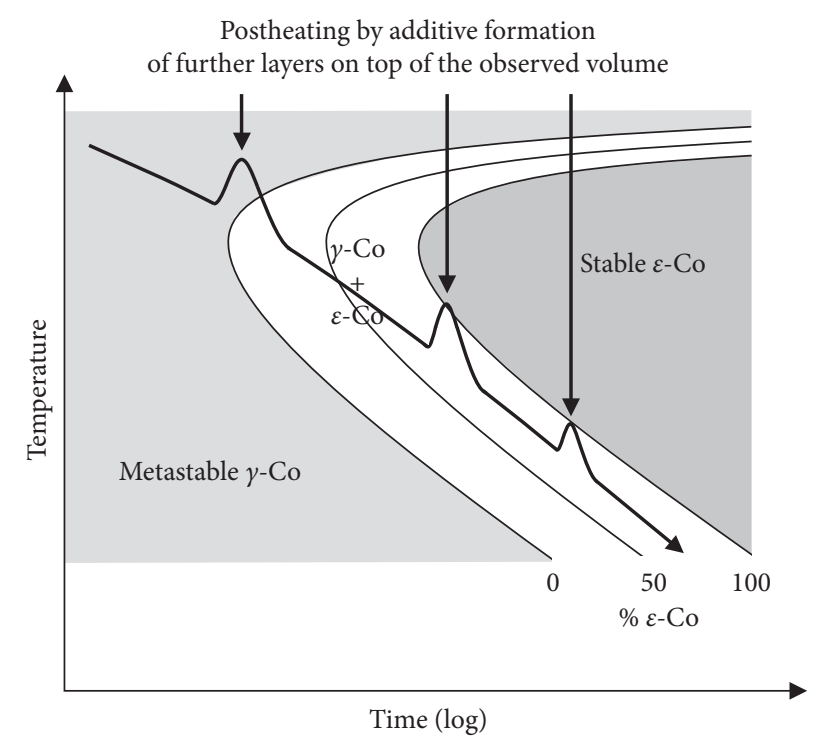

FIgURE 12: Continuous TTT diagram schematically, adapted from [38].

The divergences observed in $\mathrm{AB}$ conditions are possibly due to varying irradiation in the printing or manufacturing systems. In the heat-treated condition, the differences observed are related to the partial recrystallization that occurred at $800^{\circ} \mathrm{C}$ in comparison to the full recrystallization at $1150^{\circ} \mathrm{C}$ followed by furnace cooling, allowing thermodynamic equilibrium conditions. Apart from the $\mathrm{HV}$ values, $E$, $R_{\mathrm{P} 0.2}, A_{\mathrm{t}}$, and $R_{\mathrm{m}}$ are higher in Co-Cr-W than in Co-Cr-Mo. This simultaneous increase in their respective $\mathrm{AB}$ conditions could be an indication that the C-formed curves of the TTT diagram (Figure 11) are moved to lower times for the Co-Cr$\mathrm{W}$ alloy. Applying the annealing heat treatment, $E$ and $A_{\mathrm{t}}$ (except for $\Phi=90^{\circ}$ ) increased, whilst $R_{\mathrm{P} 0.2}, R_{\mathrm{m}}$, and $\mathrm{HV}$ of Co-Cr-W decreased.

Concerning the standards requirements for Type 5 dental alloys, both alloys can be considered suitable for clinical use in their heat-treated condition. Although AB Co-Cr-W also fulfills these requirements, a heat treatment is highly recommended, not only to minimize possible distortions from residual stress, but also to enhance the ductility and stiffness of the material. To guarantee the integrity of the built parts, it is recommended that heat treatment be performed on built parts whilst they are firmly attached to the support structure on the substrate plate. $E$ and $R_{\mathrm{m}}$ values provided by the Co-Cr-W manufacturer are somewhat comparable to ours. $A_{\mathrm{t}}$ values at $0^{\circ}$ and $90^{\circ}$ in this study are higher than those of the manufacturer, whereas our $R_{\mathrm{P} 0.2}$ values are lower. The higher and arbitrary $R_{\mathrm{m}}$ values for the Co-Cr-Mo alloy may be due to the increased surface roughness of the specimens or the possible subsurface porosity acting as crack initiation [9]. However, these prospective "inhibitors" were absent in the machined Co-Cr-W specimens with documented studies suggesting the machining process results in improved mechanical properties by enhancing $R_{\mathrm{m}}$ by $5-10 \%$ and $E$ up to $10 \%$ [39-41].
4.3. Hardness. In our study, we observed minor deviations between microhardness (HV5) and macrohardness (HV20). However, data from the microhardness (HV5) tests might be prone to fluctuations due to limited indentation depth (approximately $20 \mu \mathrm{m}$ at $380 \mathrm{HV} 5$ ), which is lower than a single layer $(\sim 30 \mu \mathrm{m})$ and thus may not be a conclusive measure (Figure 13). For comparison, the indentation depth for 380 HV20 is approximately $40 \mu \mathrm{m}$. The hardness tests did not reveal any significant fluctuations regarding the sample orientation. In addition, both alloys exhibited similar HVs in their $\mathrm{AB}$ conditions, despite the differences in their $R_{\mathrm{P} 0.2}$ and $R_{\mathrm{m}}$ values. In their respective HT conditions, $\mathrm{HV}$ values differ ( $\sim 35 \mathrm{HV}$ for Co-Cr-Mo and $\sim 360 \mathrm{HV}$ for Co-Cr-W), but with comparable $R_{\mathrm{m}}$ values. The disparity between $\mathrm{HV}$ values and tensile properties is possibly because hardness testing focuses on compressive stresses, whereas the tensile test produces failure at uniaxial forces. It is documented that the mechanical properties of SLM-produced alloys do differ in regard to tensile versus compressive loading [42]. Moreover, it is known that the conclusion from hardness to tensile strength is problematic for selective laser-melted metals [10].

\section{Conclusion}

In this study, we assessed the clinical properties of lasermelted Co-Cr-Mo and Co-Cr-W alloys in as-built and heattreated conditions. The anisotropy observed in the alloys primarily influenced ductility in addition to minor fluctuations in tensile strength and Young's modulus. In the as-built condition, the alloys displayed reduced Young's modulus and hence required heat treatment to meet clinical requirements set out in the standards. Similarly, heat treatment is recommended if the desired ductility and isotropic characteristics are to be guaranteed. Although the study confirms the capacity of the SLM systems to produce consistent parts under controlled manufacturing parameters, further 


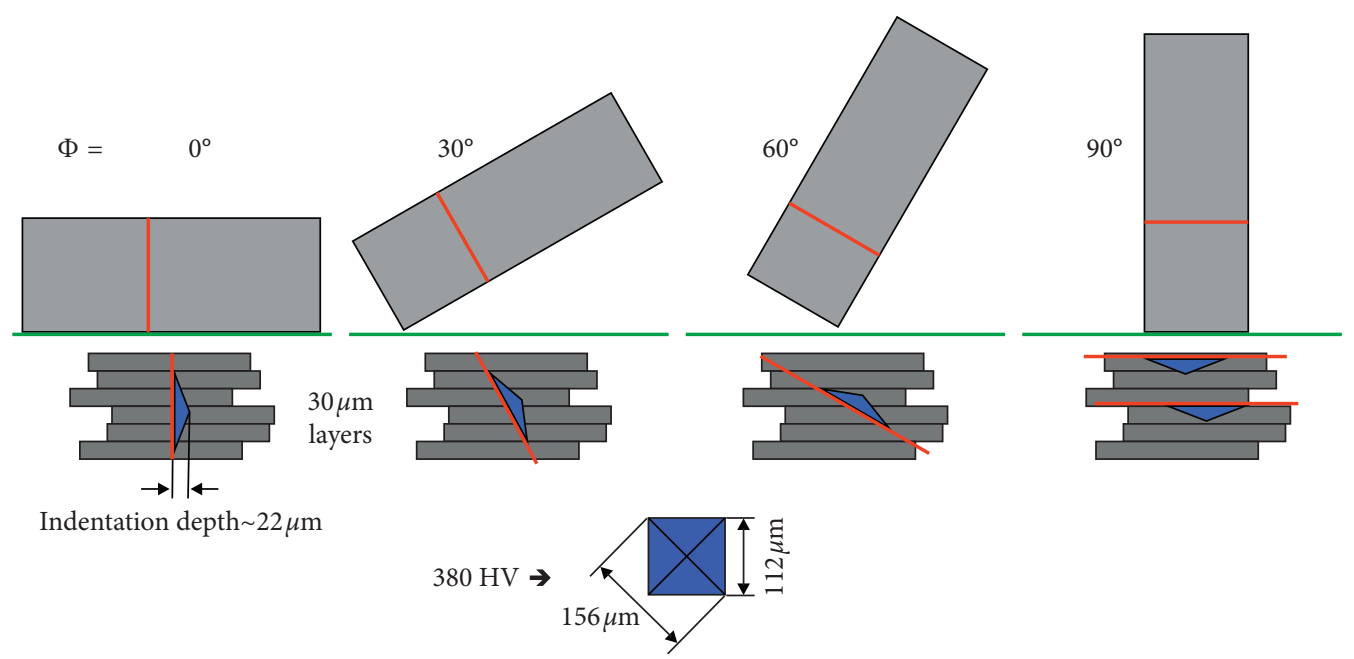

FIGURE 13: Indentation depth versus layer thickness.

microstructure analysis could shed light on phase contents and their alteration via the applied heat treatments.

\section{Data Availability}

Data obtained for this work are provided in the results section. When additional data/results were taken to validate or confirm statements, the source has been cited accordingly.

\section{Disclosure}

Leonhard Hitzler and Frank Alifui-Segbaya are co-first authors.

\section{Conflicts of Interest}

The authors declare that they have no conflicts of interest.

\section{Acknowledgments}

The authors would like to thank Objective 3D (Australia) for kindly supplying the Remanium star CL samples and 3D Systems (Australia) for supplying the ST2724G samples for the study.

\section{References}

[1] E. Haynes, Metal Alloy, U.S.P. Office, Washington, DC, USA, 1907.

[2] A. K. Mishra, M. A. Hamby, and W. B. Kaiser, "Metallurgy, microstructure, chemistry and mechanical properties of a new grade of cobalt-chromium alloy before and after porouscoating," in Cobalt-Base Alloys for Biomedical Applications, J. A. Disegi, R. L. Kennedy, and R. Pilliar, Eds., ASTM, West Conshohocken, PA, USA, 1999.

[3] R. Van Noort, Introduction to Dental Materials, Elsevier, Amsterdam, Netherlands, 2013.

[4] F. Alifui-Segbaya, P. Foley, and R. J. Williams, "The corrosive effects of artificial saliva on cast and rapid manufacture- produced cobalt chromium alloys," Rapid Prototyping Journal, vol. 19, no. 2, pp. 95-99, 2013.

[5] F. Alifui-Segbaya, R. J. Williams, and R. George, "Additive manufacturing: a novel method for fabricating cobaltchromium removable partial denture frameworks," European Journal of Prosthodontics and Restorative Dentistry, vol. 25, no. 2, pp. 73-78, 2017.

[6] F. Alifui-Segbaya, J. Evans, D. Eggbeer, and R. George, "Clinical relevance of laser-sintered $\mathrm{Co}-\mathrm{Cr}$ alloys for prosthodontic treatments: a review," in Proceedings of the 1st International Conference on Progress in Additive Manufacturing, pp. 115-120, Singapore, May 2014.

[7] Food and Drug Administration, Technical Considerations for Additive Manufactured Devices: Draft Guidance for Industry and Food and Drug Administration Staff, Food and Drug Administration, Silver Spring, MD, USA, 2016.

[8] L. Hitzler, J. Hirsch, B. Heine, M. Merkel, W. Hall, and A. Öchsner, "On the anisotropic mechanical properties of selective laser melted stainless steel," Materials, vol. 10, no. 10, p. 1136, 2017.

[9] L. Hitzler, C. Janousch, J. Schanz et al., "Direction and location dependency of selective laser melted AlSi10Mg specimens," Journal of Materials Processing Technology, vol. 243, pp. 48-61, 2017.

[10] L. Hitzler, M. Merkel, W. Hall, and A. Öchsner, "A review of metal fabricated with laser- and powder-bed based additive manufacturing techniques: process, nomenclature, materials, achievable properties, and its utilization in the medical sector," Advanced Engineering Materials, vol. 20, no. 5, article 1700658, 2018.

[11] S. Yager, J. Ma, H. Ozcan, H. I. Kilinc, A. H. Elwany, and I. Karaman, "Mechanical properties and microstructure of removable partial denture clasps manufactured using selective laser melting," Additive Manufacturing, vol. 8, pp. 117-123, 2015.

[12] A. Takaichi, Suyalatu, T. Nakamoto et al., "Microstructures and mechanical properties of Co-29Cr-6Mo alloy fabricated by selective laser melting process for dental applications," Journal of the Mechanical Behavior of Biomedical Materials, vol. 21, pp. 67-76, 2013.

[13] F. Alifui-Segbaya, J. Lewis, D. Eggbeer, and R. J. Williams, "In vitro corrosion analyses of heat treated cobalt-chromium alloys manufactured by direct metal laser sintering," Rapid Prototyping Journal, vol. 21, no. 1, pp. 111-116, 2015. 
[14] SINT-TECH, ST2724G - Technical Data: Type 5 CoCrMo Dental Alloy, Riom, France, 2014.

[15] Concept-Laser, Technical Data in Line with DIN EN ISO 9693/ DIN EN ISO 22674 after Recommended Heat Treatment, Concept-Laser, Lichtenfels, Germany, 2017, https://www. concept-laser.de/fileadmin//user_upload/Datasheet_remanium_ star_CL.pdf.

[16] British Standards Institution, BS EN ISO 22674-Dentistry: Metallic Materials for Fixed and Removable Restorations and Appliances, British Standards Institution, London, UK, 2016.

[17] 3D Systems, ProX DMP 200, 3D Systems, Rock Hill, SC, USA, 2018, https://au.3dsystems.com/3d-printers/prox-dmp-200.

[18] Concept Laser GmbH, Remanium Star CL Powered by Dentaurum, Concept Laser GmbH, Lichtenfels, Germany, 2017, https://www.concept-laser.de/fileadmin//user_upload/ Datasheet_remanium_star_CL.pdf.

[19] International Organization for Standardization, ISO 22674: 2016: Dentistry - Metallic Materials for Fixed and Removable Restorations and Appliances, International Organization for Standardization, Geneva, Switzerland, 2016.

[20] Deutsches Institut fuer Normung e.V., DIN EN ISO 6892-1, Metallic Materials_Tensile Testing-Part 1: Method of Test at Room Temperature, Beuth Verlag, Berlin, Germany, 2016.

[21] Deutsches Institut fuer Normung e.V., DIN EN ISO 6507-2, Metallic Materials_Vickers Hardness Test-Part 2: Verification and Calibration of Testing Machines, Beuth Verlag, Berlin, Germany, 2016.

[22] A. B. Spierings, M. Schneider, and R. Eggenberger, "Comparison of density measurement techniques for additive manufactured metallic parts," Rapid Prototyping Journal, vol. 17, no. 5, pp. 380-386, 2011.

[23] H. Wulfes, Precision Milling and Partial Denture Constructions, Academia Dental International School BEGO Germany, Bego, Bremen, Germany, 2004.

[24] J. C. Wataha, "Alloys for prosthodontic restorations," Journal of Prosthetic Dentistry, vol. 87, no. 4, pp. 351-363, 2002.

[25] 3D Systems, CoCrMo Alloy for ProX ${ }^{\mathrm{TM}}$ 100, 200 and 300 Direct Metal Printers, 3D Systems, Rock Hill, SC, USA, 2015, https:// www.3dsystems.hu/content/pdf/cocrmo_alloy_us_0615_ press.pdf.

[26] S. Leuders, M. Thöne, A. Riemer et al., "On the mechanical behaviour of titanium alloy TiAl6V4 manufactured by selective laser melting: fatigue resistance and crack growth performance," International Journal of Fatigue, vol. 48, pp. 300-307, 2013.

[27] T. Vilaro, C. Colin, and J. D. Bartout, "As-fabricated and heattreated microstructures of the Ti-6Al-4V alloy processed by selective laser melting," Metallurgical and Materials Transactions A, vol. 42, no. 10, pp. 3190-3199, 2011.

[28] S. P. Faure, L. Mercier, P. Didier et al., "Laser sintering process analysis: application to chromium-cobalt alloys for dental prosthesis production," in Proceedings of Biennial Conference on Engineering Systems Design and Analysis, ESDA 2012, pp. 9-15, ASME, Nantes, France, 2012.

[29] L. Hitzler, P. Williams, M. Merkel, W. Hall, and A. Öchsner, "Correlation between the energy input and the microstructure of additively manufactured cobalt-chromium," Defect and Diffusion Forum, vol. 379, pp. 157-165, 2017.

[30] A. Öchsner, Continuum Damage and Fracture Mechanics, Springer, Berlin, Germany, 2016.

[31] L. Hitzler, C. Janousch, J. Schanz, M. Merkel, F. Mack, and A. Öchsner, "Non-destructive evaluation of AlSi10Mg prismatic samples generated by selective laser melting: influence of manufacturing conditions," Materialwissenschaft und Werkstofftechnik, vol. 47, no. 5-6, pp. 564-581, 2016.

[32] J. Schanz, M. Hofele, S. Ruck et al., "Metallurgical investigations of laser remelted additively manufactured AlSi10Mg parts," Materialwissenschaft und Werkstofftechnik, vol. 48, no. 5, pp. 463-476, 2017.

[33] P. B. Hirsch, A. Howie, R. Nicholson, D. W. Pashley, and M. J. Whelan, Electron Microscopy of Thin Crystals, Butterworth and Co. Publishers Ltd., London, UK, 1965.

[34] Y. Kajima, A. Takaichi, N. Kittikundecha et al., "Effect of heattreatment temperature on microstructures and mechanical properties of $\mathrm{Co}-\mathrm{Cr}-\mathrm{Mo}$ alloys fabricated by selective laser melting," Materials Science and Engineering: A, vol. 726, pp. 21-31, 2018.

[35] P. Huang and H. F. López, "Athermal $\varepsilon$-martensite in a CoCr-Mo alloy: grain size effects," Materials Letters, vol. 39, no. 4, pp. 249-253, 1999.

[36] C. H. Savage, Heat-Treatment of Cobalt Base Alloys and Products, U.S.P. Office, Washington, DC, USA, 1946.

[37] R. Turrubiates-Estrada, A. Salinas-Rodriguez, and H. F. Lopez, "FCC to HCP transformation kinetics in a $\mathrm{Co}-27 \mathrm{Cr}-5 \mathrm{Mo}-$ 0.23C alloy," Journal of Materials Science, vol. 46, no. 1, pp. 254-262, 2011.

[38] K. C. Li, D. J. Prior, J. N. Waddell, and M. V. Swain, "Microstructure, phase content, and thermal stability of a cast Co-Cr dental alloy after porcelain sintering cycles using electron backscatter diffraction," Journal of Materials Research, vol. 30, no. 14, pp. 2188-2196, 2015.

[39] D. Zhang, Entwicklung des Selective Laser Melting (SLM) für Aluminumwerkstoffe, Fakultät für Maschinenwesen, RWTH Aachen, Aachen, Germany, 2004.

[40] J. Sehrt and G. Witt, Auswirkung des anisotropen Gefüges strahlgeschmolzener Bauteile auf Mechanische Eigenschaftswerte, RTejournal, Forum für Rapid Technologie, Duisburg, Germany, 2009.

[41] J. T. Sehrt, Möglichkeiten und Grenzen bei der Generativen Herstellung Metallischer Bauteile Durch das Strahlschmelzverfahren, Maschinenbau und Verfahrenstechnik, University Duisburg-Essen, Duisburg, Germany, 2010.

[42] L. Hitzler, N. Schoch, B. Heine, M. Merkel, W. Hall, and A. Öchsner, "Compressive behaviour of additively manufactured AlSi10Mg," Materialwissenschaft und Werkstoffechnik, vol. 49, no. 5, pp. 683-688, 2018. 


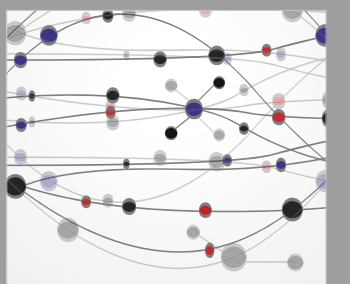

The Scientific World Journal
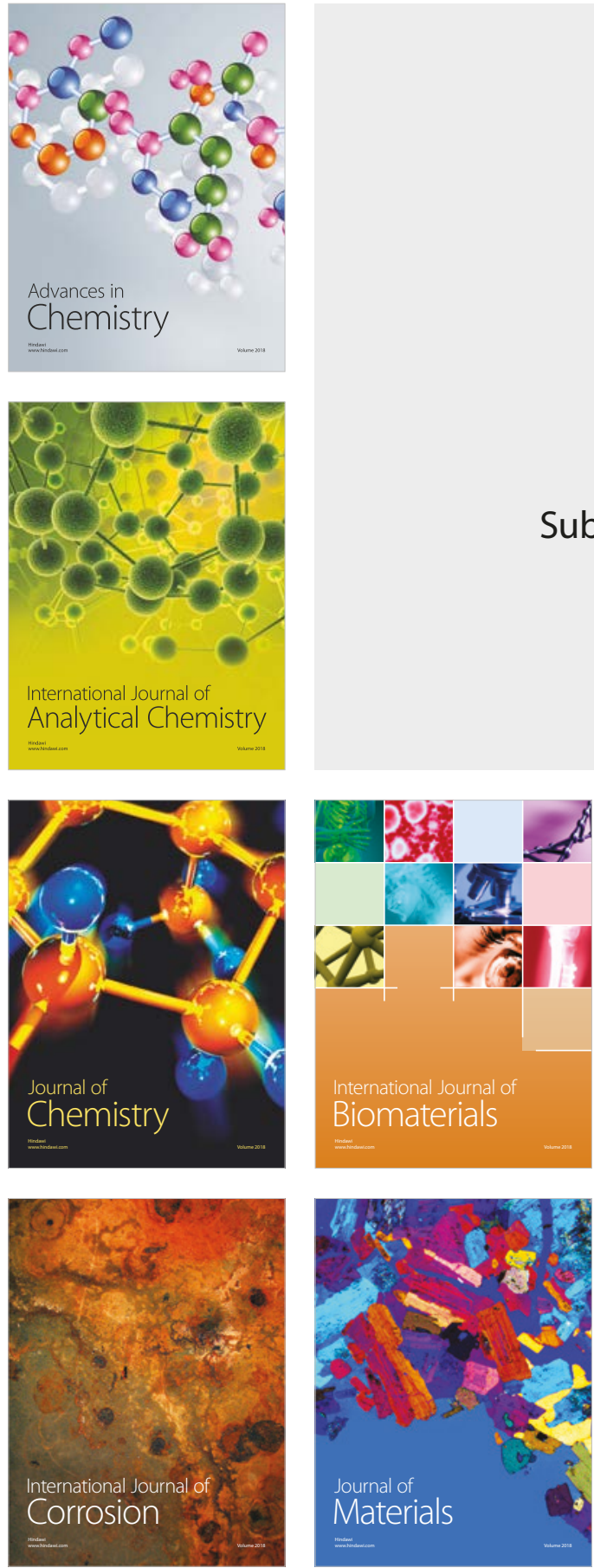

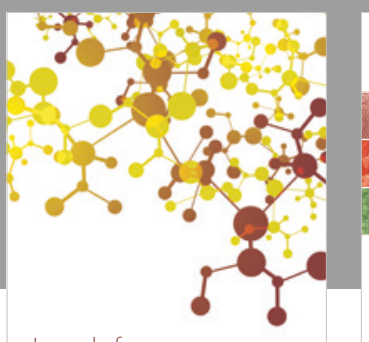

Journal of

Applied Chemistry
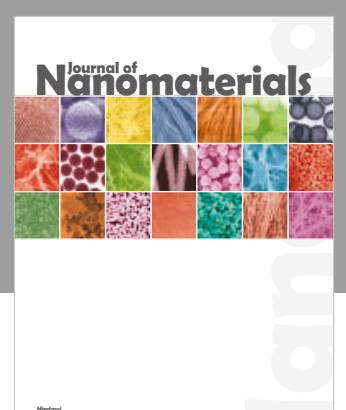

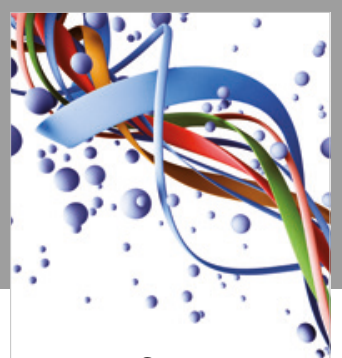

Scientifica

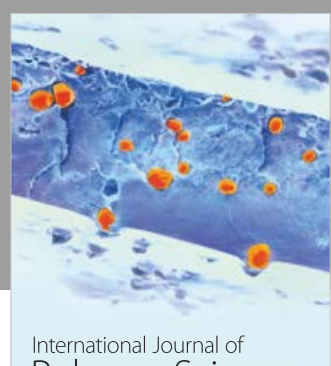

Polymer Science

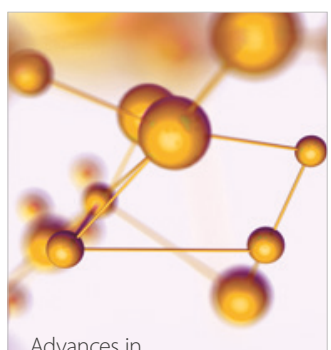

Physical Chemistry
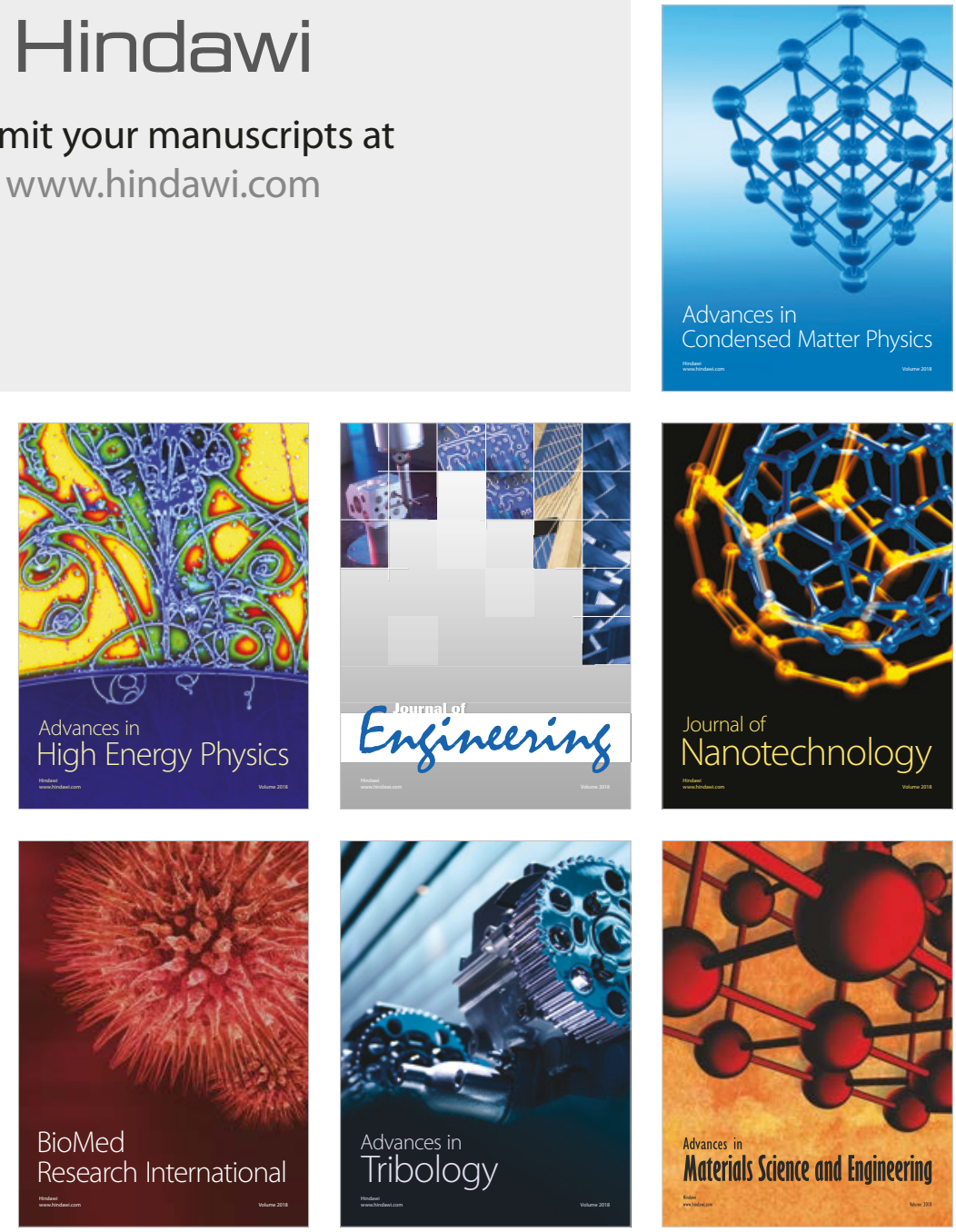